\title{
SIMULATION BASED DECISION FOR STEELMAKING OPERATIONS CHALLENGES
}

\author{
Marcelo Moretti Fioroni, MSc. \\ Luiz Augusto G. Franzese, MSc. \\ Paragon Consulting Solutions. \\ R. Clodomiro Amazonas $1435-5^{\text {th }}$ \\ São Paulo SP 1 04537-012 BRAZIL
}

\author{
Edson Luis M. Harano \\ Benedito Pedro Costhek \\ João Bosco Mendes \\ Joeli Cuzzuol \\ Juliana de Souza Lima \\ Ricardo Baeta Santos \\ Robson Jacinto Coelho \\ Adriano César Silva \\ Odair José Kimsr \\ Companhia Siderúrgica de Tubarão \\ CST Iron making Department \\ Serra, E.S. 29163-970, BRAZIL
}

\begin{abstract}
Companhia Siderúrgica de Tubarão CST, is investing to expand production level in $50 \%$, adding new equipment and altering production process. Simulation is widely used in CST, mainly in strategic phases prior to capital investment. A previous simulation model developed with ARENA was enhanced to help CST achieve new goals: to analyze new process plan with operational details, testing different production and operational scenarios, evaluating new procedures and best practices. Two case studies are presented here to show how CST uses this technology: the expansion of an steelmaking plant and the expansion of the raw material handling conveyor system.
\end{abstract}

\section{INTRODUCTION}

CST - Companhia Siderúrgica de Tubarão of Brazil Integrated Steelmaking Company. With more than 60 customers in 18 countries, CST sales reached US\$ 2.0 billions in 2004. Main products are slabs and pig iron, considered semi-manufactured products, with several industry applications, including naval, automotive, appliances, etc.

Nowadays CST is operating with 2 blast furnaces with capacity of $5.0 \mathrm{Mt} / \mathrm{y}$ of pig iron, feeding a steelmaking with 2 converters and 2 Continuous Casting Machines. New equipment configuration will increase slabs production to $7.5 \mathrm{Mt} / \mathrm{y}$.

\section{EXPANSION PROJECT}

The planning phase of this expansion project started in early 2003, with equipment selection, seeking an opera- tional start up during the second semester of 2006. The new equipment configuration will increase the slabs production to $7.5 \mathrm{Mt} / \mathrm{y}$. and will allow the ennoblement of the production mix and the reduction of the production cost.

New equipment includes a new coke oven battery, (HRCP), a third blast furnace, a third converter, desulphurization equipment, a third continuous casting machine, vacuum gas machine and auxiliary equipment (oxygen plants, thermo electrical plant, calcinations etc.).

This new configuration will require complete new operational procedures to support a $50 \%$ increase in production level, what drove design team to investigate several operation practices, in order to anticipate problems and define in advance their new operational standards.

\section{STEEL MAKING SIMULATION MODEL}

Initially developed under ARENA 2.0, the Steel Making Simulation model has been used and enhanced for almost a decade, reaching ARENA version 8.0 recently. The simulation model received even more operation detail to help identify operational gaps and estimate production level and workload.

Since converters offer batch production and Casting machines are continuous, steel availability is mandatory, otherwise casting machines will stop production, causing new setup and reduction in productivity and efficiency. This synchronism is vital.

In order to analyze in detail all operational procedures, a previous simulation model, developed by PARAGON Consulting Solutions with ARENA simulation software, was enhanced through a joint effort project, in order to help testing and anticipate operational challenges and bot- 
Fioroni, Franzese, Harano, Costhek, Mendes, Cuzzuol, Lima, Santos, Coelho, Silva, and Kimsr

tlenecks. One of the key issues in the model was to emulate support equipment role (overhead cranes, torpedo cars etc.), testing if Steelmaking could handle production increase of $50 \%$.

According to each scenario chosen, simulation model allows evaluation of production and effects in all equipment, according to operational procedures adopted. Usage of detailed animation provided an excellent visualization of future problems. This allowed several decisions, and will assure consistent operational cost reduction, since some policies will not be used anymore. Figure 1 presents overview of animation layout while Figure 2 presents detail of converters.

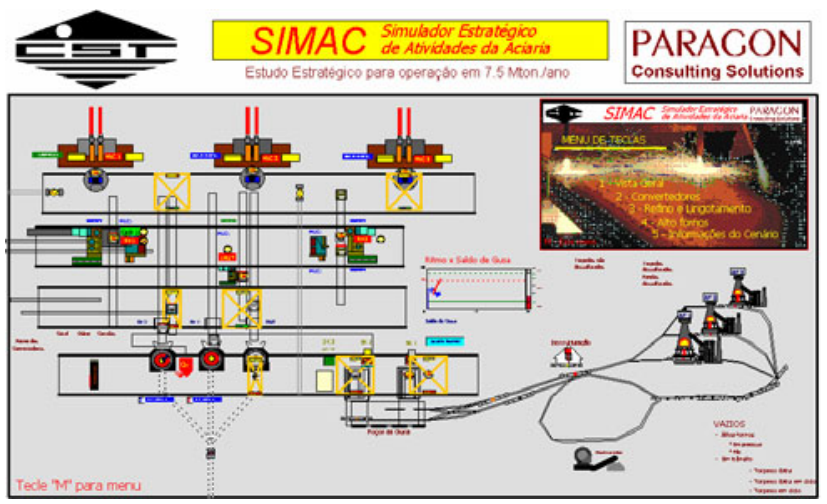

Figure 1: Overview Animation Layout

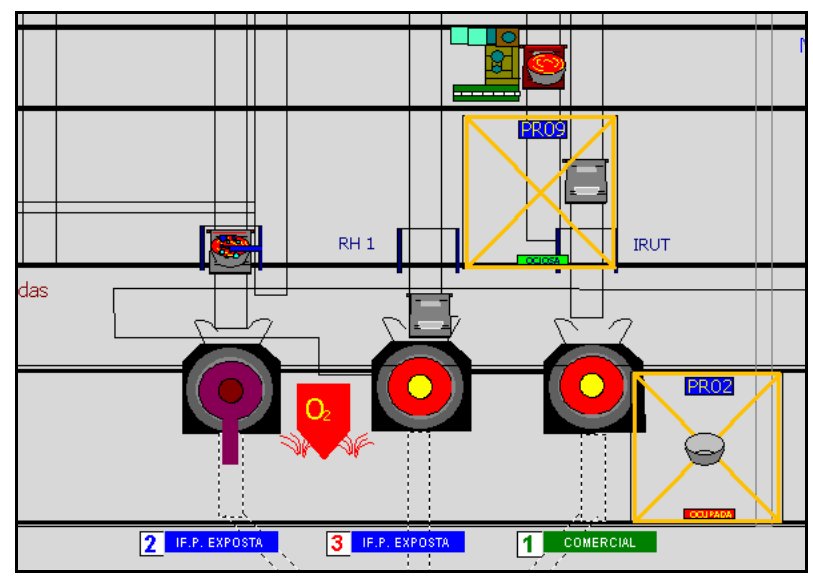

Figure 2: Converters Animation

The model represents precisely real system with accuracy, considering maintenance and its effect on production flow. And to facilitate scenario evaluation, a user interface was developed using Microsoft Excel, to allow different type of users to perform simulations and analyze results. Almost 100 options are available. Figure 3 shows User Interface while Figures 4 and 5 shows equipment configuration and maintenance options.

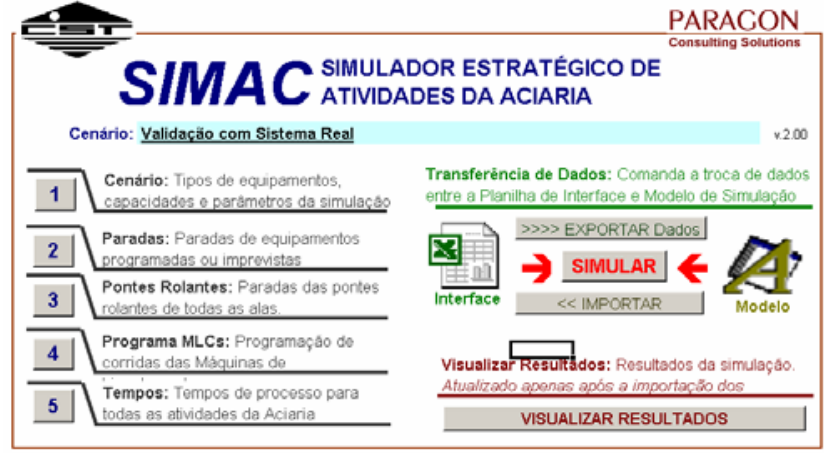

Figure 3: User interface

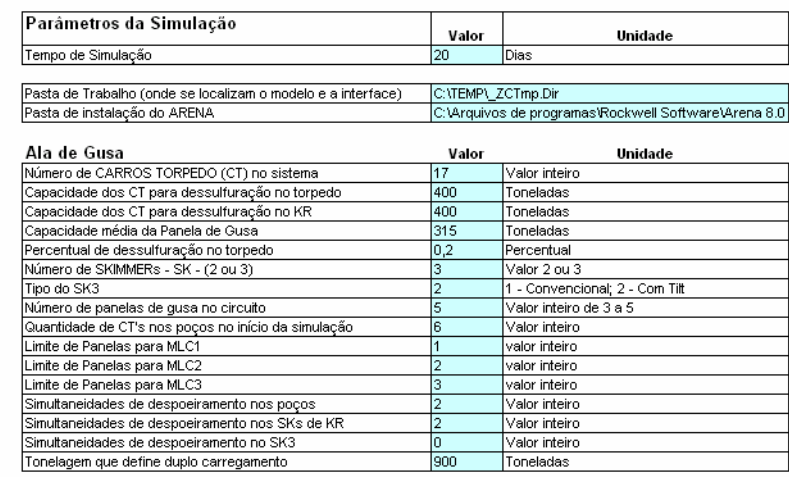

Figure 4: Equipment configuration

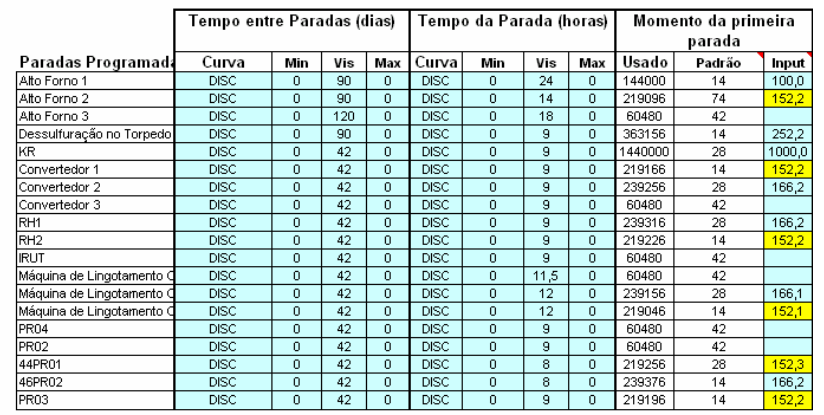

Figure 5: Maintenance options

Since production is actually pulled from Continuous Casting machines, and follows characteristics of speed, size and width, it is necessary to provide scheduling information to the simulation model, as described in Figure 6.

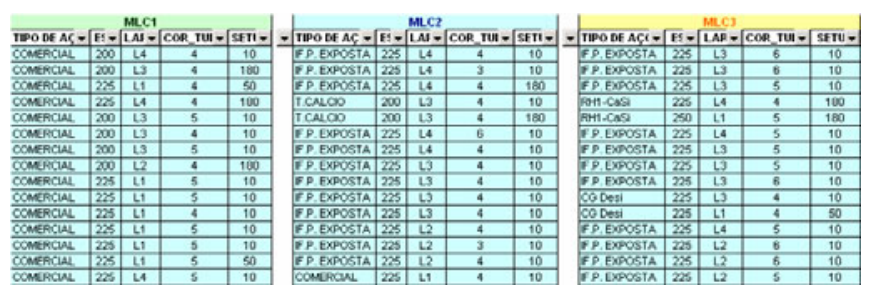

Figure 6: Continuous Casting Scheduling 


\subsection{Validation and Experimentation}

Several scenarios matching actual reality were simulated, in order to validate simulation model output, with impressive results due to a relative small deviation found. After validation phase, expansion scenarios were then created.

Some quantitative results are presented in figure 7 focusing main variables. More detailed results of scenarios cannot be made available at this time since expansion is still in progress.

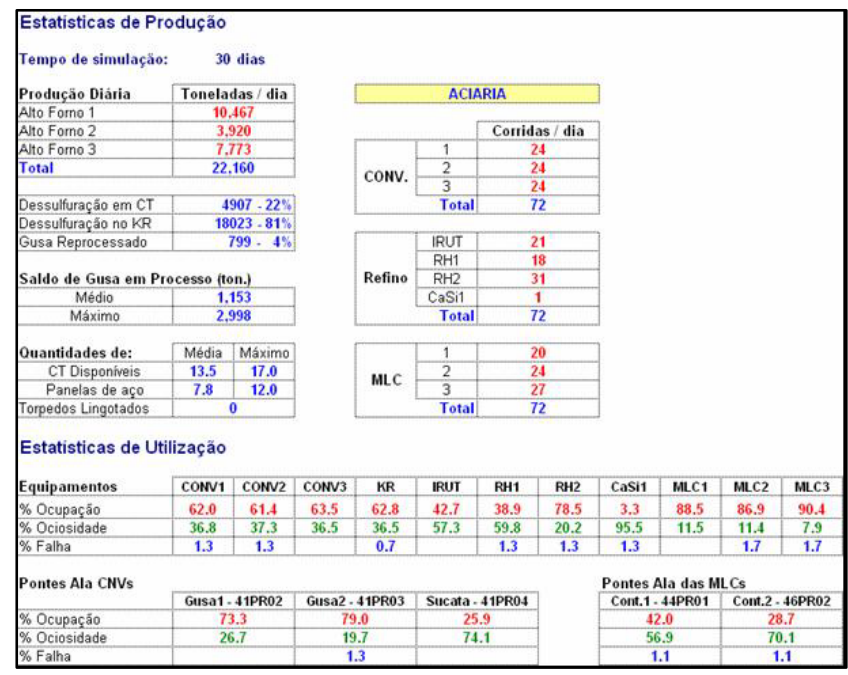

Figure 7: Main Results

\subsection{Results}

Model demonstrated that proper priority to Continuous Casting Machine \# 3 is necessary, due to increased productivity, leaving CCM \#1 and \#2 with lower priorities. This will lead into different production routes, based on system state, tested and approved by the simulation model.

Previous expectation of using dedicated converters for each continuous casting machine was abandoned, since this operational practice produces negative impact in synchronism. But model demonstrated benefits of independent choice of continuous casting based on a sort of FIFO rule.

Simulation also offered positive insights for scheduling department, to aid further development into operational control software. Production level can reach more than expected, being able to produce up to 8.0 Mton per year with equipment and production practices chosen.

\section{YARD PROJECT}

The Raw material receiving area of a steel work integration plant is the beginning process of a productive cycle, which the final productive are the several steel products. In this context, the receiving area needs operate with quality guaranty for the supply these materials in good operation condition and low cost.

The quality and cost of the final product are intimately connected to the initial process step (Fioroni et.al., 2004). Also due to investments and production cost, supply area usually demands proper care and attention, since lack of materials may hurt production (with production loss or even worse: equipment loss). Receiving system includes 4 main elements:

- Receiving of raw material through a rail car dumper, a truck-rail hopper as well as from a direct conveyor (from CVRD Mining - Vale do Rio Doce to CST)

- Stockpiling all received material along 6 yards, with 4 of them dedicated to raw material and 2 to blended materials.

- Material processors, that consume and converted raw material into other products, for internal usage in the system;

- Material Consumers, that only receive material for consumption.

Receiving area, with a rail car dumper, a rail-truck hopper as well as yards, must assure that certain demands are fulfilled, specially from :

- Safety/minimum Level for inventory, at lower cost possible

- Piling and un-piling from yards

- Operational procedures for conveyors and pile feeding.

Binding to all these elements, it has a complex system composed for 155 transporting leather straps, capable to take the materials of its points of origin until the destination, either for storage or consumption. There are at least 269 distinct routes in the future system, taking care of to the most diverse necessities of movement.

There are several types of raw materials, which are sent to be processed or consumed. Processed includes:

- Blending (mixture of some materials with distinct characteristics).

- Sintering, an agglomeration process whose resultant product, sinter, presents chemical characteristics, physical and metallurgic compatible with the requests of the blast furnace.

Raw material consumption is made are three blast furnaces, that produce steel. These have absolute priority of attendance, since the lack of materials means loss of production. Beyond blast furnaces, it has the whitewash plant (Calcination), that it consumes three different types of calcareous rock. 
Each point of consumption or processing of materials works with silos that store a certain amount of material to be consumed. In the four patios, any type of raw material can be stored, except blended one, that it has others two dedicated patios. Between each two patios, there is Stacker-Reclaimer equipment. System still posses some bolters, whose purpose is to classify the materials, sent to the blast furnaces. When passing through them, part of the original material is deviated and classified as another material.

Current system works with only two blast furnaces, in a way that the volume of consumed raw material is sufficiently different of that it occur expansion adds a third blast furnace. There are doubts about occupation of future conveyor system and occupations, bottlenecks and operation rules. The schematic diagram of the system is presented in the Figure 8.

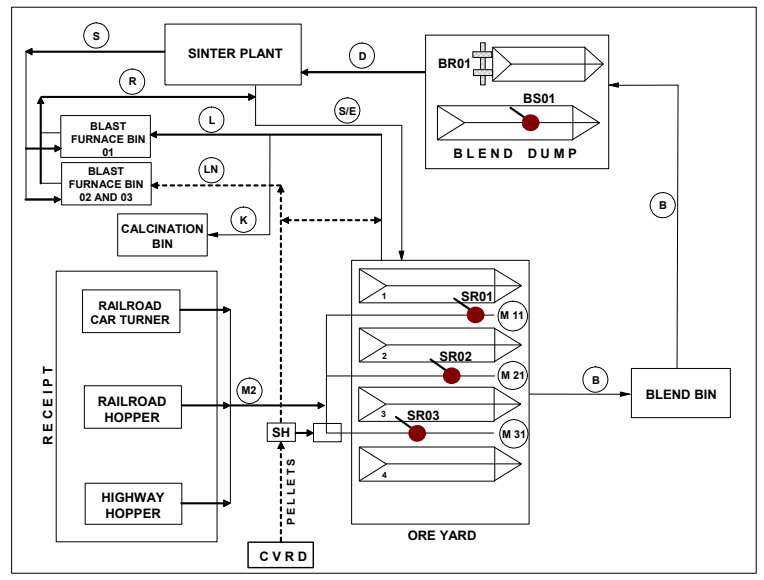

Figure 8: Schematic Diagram CST

\subsection{Raw Material Yard Simulation Model}

In order to analyze in detail this system, CST contracted PARAGON Consulting Solutions, and adopted ARENA simulation software. Project was developed through a joint effort, in order to help testing and anticipate operational challenges and bottlenecks.

Initially, the conceptual model was divided in two distinct modules, with independent operation:

- Module of supply and raw material consumption: congregating all the points of origin and raw material destination in the system. It is responsible for detecting the necessity of a determined raw material in local, identifying a point of supply of this material and to make its solicitation of transport;

- Module of transport: it represents the transport system that binds the origin points to the destination points. It receives order from transport of the module of supply and consumption, and must be capable to identify to which the route of leather straps capable to take the material of the origin point to the destination point. When a leather strap of the route will be busy, the system looks another route, or waits, case all the route options is blocked.

The system was prepared to function through level monitoring of silo levels, generating orders when volume reached a level of individual re-supply. But it was evidenced through experiments that this simple rule would not be enough, so that the system functioned without having fall down-cement in the silos of the blast furnaces.

It was evidenced that determined joint of leather straps were busy for too much time, hindering some critical loads. Such situations could not be dealt with only automatic form, as conceived originally. These problems had been taken to the designers of the system, who had suggested improvements in the rules of the model.

Thus, the original rule was being gradual improved, receiving exceptions from behavior, asked for determined priorities of attendance in, and to force the operation of the system of specific form in determined situations.

Of this form, its behavior was more similar the operation under supervision human being, improving significantly its performance, until more not having occurrence of lack of material in the blast furnaces..

The model was animated over Autocad layout, what allowed following process in detail and evaluating actions and events of the simulation. Images of the animation are shown in Figure 9.

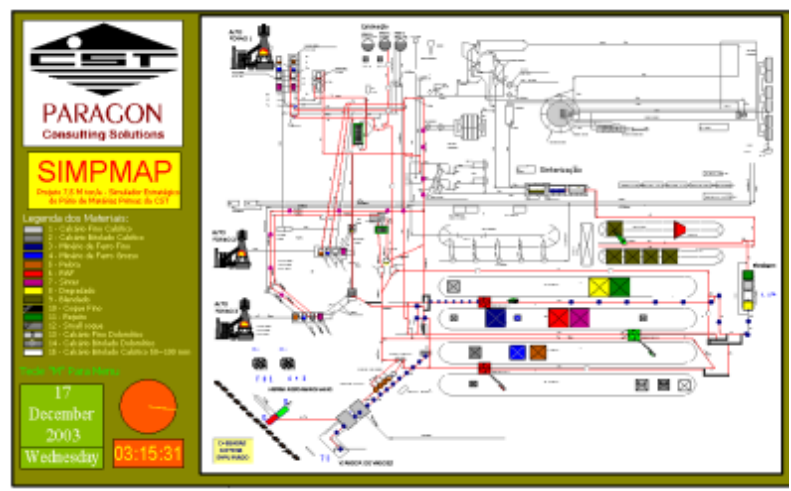

Figure 9: General Animation Layout

Also an interface for model operation was developed, using MS Excel, allowing scenario testing for different type of professionals, which knew the systems but were newcomers to simulation.

Besides allowing parameters change, interface also presents results of the simulation, facilitating its posterior use. Figure 10 presents some images of the interface. 


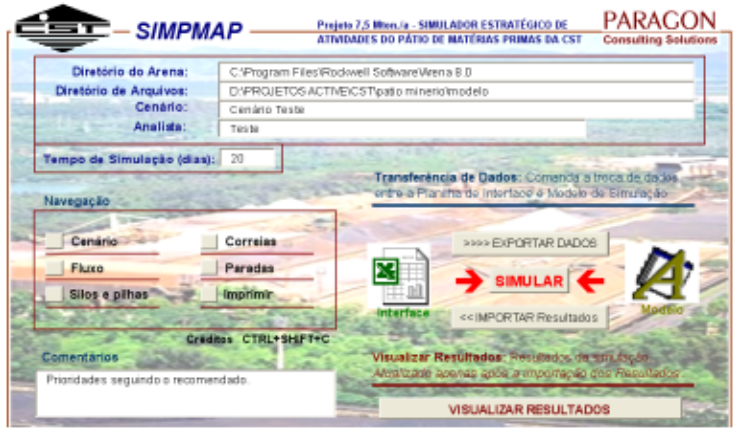

Figure 10: User interface

The interface qualifies the user to modify dozens of following parameters of the system, while the most important are:

- Volume of external arrivals of material and its modal one of transport: trucks, rail cars and car dumper information.

- Capacity of each truck or wagon and size of the compositions;

- Allocation of the materials in the four available patios;

- Initial Volume of the stacks of material in the patios;

- Silos: initial volume, reorder point, order volume and maximum capacity;

- Daily Consumption of material in each point of the system that receives material;

- Daily Production of sinter and blended material;

- Income of the bolters of the system for each bolted material;

- Capacity of transport of conveyor for each type of carried material;

- Equipment maintenance.

\subsection{Experimentation}

Scenario initially studied was inspired by original project. During this simulation was confirmed the suspicion: conveyor systems and operational rules were not effective to assure production demand. These restrictions produced as consequence lack of some raw materials in the blast furnaces.

More than 60 scenarios were created to evaluate new rules. Due to model flexibility and ability to quickly add new rules to model logic, complete sets of operational rules were created and tested during this phase.

After that, a significant increase of conveyor capacity as well new set of rules and priorities were established, producing excellent results for the system. Some of the results, including inventory levels, can be seen in figure 11.

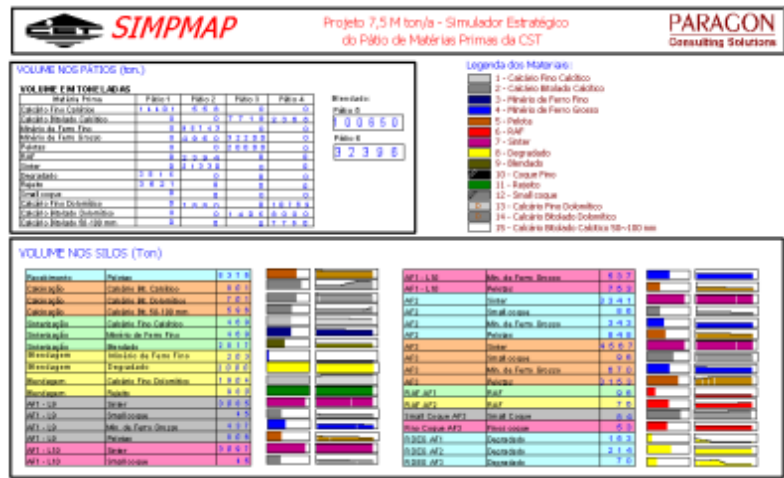

Figure 11: Inventory Levels

\section{CONCLUSIONS}

The CST Steel Making simulator is a powerful and flexible tool that is used for almost a decade, aiding CST engineers to evaluate scenarios for strategic, tactical and operational purposes.

Proper demonstration and animation, as well as solid results offer a powerful combination to final customers, i.e. Production Managers, so they can test drive their systems even before they are purchased.

Proper demonstration and animation, as well as solid results offer a powerful combination to final customers, i.e. Production Managers (Scarpe 1998), so they can test drive their systems even before they are purchased .

The simulation of the Raw Material Yard allowed a deep analysis of a complex system, and assisted investment decision. Below some signaled conclusions:

- With the specific consumption of "small coke" of $48 \mathrm{Kg} / \mathrm{ton}$, as established by ERP is possible to supply the blast furnaces.

- Conveyor System D and Blend Reclaimer work currently to an average productivity of 800 tons per hour and to take care of the demand of $7,5 \mathrm{Mt} / \mathrm{y}$ it will have to work to an average productivity of 1250 tons per hour.

- Conveyor System B and Blend Stacker work currently to an average productivity of 1555 tons per hour and to take care of the demand of 7,5Mt/y it will have to work to an average productivity of 2200 tons per hour.

- During sinter maintenance stops, it is not possible to supply calcination. Safety inventory must be created.

- Conveyor System K working with current productivity of 595 tons per hour does not take care of demand, facing competition for raw material manuscript in system L. 
Fioroni, Franzese, Harano, Costhek, Mendes, Cuzzuol, Lima, Santos, Coelho, Silva, and Kimsr

Further development will continue, since several new ideas for production increase have arise, what will expand lifetime of both simulation models.

\section{ACKNOWLEDGEMENTS}

The authors thanks CST Operational Managers and Engineers for their continued support on this project.

\section{REFERENCES}

Scarpe, A. A.; Mariante , W.; Franzese, L. A. G. (1998) CST Steel Shop Operation Model. ArenaSphere98.

Kelton, D. W., Sadowski, R. P., Sadowski , D. A. (2003) Simulation With Arena. McGraw Hill. New York.

Bapat, V.; Sturrock, D. T. (2003) - The Arena Product Family: Enterprise Modeling Solutions. Proceedings of the 2003 Winter Simulation Conference.

Fioroni M., Botter R. C.; Pompermayer , F. M.; Franzese L. A. G. (2004) - Estudo Estratégico de Dimensionamento da Infra-Estrutura do Pátio Ferroviário de Tubarão Através de Simulação. Anais do XVIII ANPET, 8-12 nov., Florianópolis-SC. Brasil.

\section{AUTHOR BIOGRAPHIES}

LUIZ AUGUSTO G. FRANZESE is a simulation consultant with a Production Engineering and MSc. in Logistics background, who has completed almost 150 successful projects with simulation. Founded PARAGON Tecnologia in 1992, the pioneer and leading consulting company in simulation in South America. Has trained more than 1,200 professionals in simulation. He can be contacted by email at <paragon@paragon. com. br>

MARCELO MORETTI FIORONI is a simulation consultant with an Electrical Engineering degree, MSc. in Manufacturing and under Logistics $\mathrm{PhD}$ program. Has participated in almost 150 successful projects with simulation. Co-founder of PARAGON Tecnologia in 1992, the pioneer and leading consulting company in simulation in South America. Teaches OR and Simulation at FPJ and FISP. Has trained more than 1,200 professionals in simulation. $\mathrm{He}$ can be contacted by email at <marcelo@paragon.com.br>

EDSON LUIS M. HARANO is a Mining Engineer at CST, with under Environmental Engineering. He can be contacted by email at <haranodcst. com. br $>$

JULIANA DE SOUZA LIMA is a Civil Engineer at CST, with M.Sc Production Engineering. She can be contacted by email at <julima@cst. com. br $>$
JOÃO BOSCO MENDES is a Metallurgical Engineer at CST, with under Master Businness Administration. He can be contacted by email at <bosco@cst. com. br>

JOELI CUZZUOL is an Account at CST, student of M.Sc Production Engineering. He can be contacted by email at $<$ joeli@cst. com.br $>$

RICARDO BAETA SANTOS is a Metallurgical Engineer at CST, with under Production Engineering. He can be contacted by email at <r. baeta aterra. com . br $>$

ROBSON JACINTO COELHO is a Metallurgical Engineer at CST, with M.Sc Materials Engineering. He can be contacted by email at <rcoelho@ cst . com. br $>$

BENEDITO PEDRO COSTHEK is a senior engineer at CST, with Industrial Engineering degree and under Logistics Master in Production program. He can be contacted by email at $<$ bchostek@cst. com . br $>$

ADRIANO CÉSAR SILVA is metallurgic engineer at CST, with Management MBA degree. He can be contacted by email at <adrianocacst. com. br>

ODAIR JOSÉ KIMSR is Senior Analyst at CST, with Computer Sciences degree and under Materials Engineering MSc. Program. He can be contacted by email at <odairacst. com. br> 